\title{
BMJ Open Adverse events in patients in home healthcare: a retrospective record review using trigger tool methodology
}

\author{
Kristina Görel Ingegerd Schildmeijer, ${ }^{1}$ Maria Unbeck, ${ }^{2,3}$ Mirjam Ekstedt, ${ }^{1,4}$ \\ Marléne Lindblad, ${ }^{5,6}$ Lena Nilsson ${ }^{7}$
}

To cite: Schildmeijer KGl, Unbeck M, Ekstedt M, et al. Adverse events in patients in home healthcare: a retrospective record review using trigger tool methodology. BMJ Open 2018;8:e019267. doi:10.1136/ bmjopen-2017-019267

- Prepublication history for this paper is available online. To view these files, please visit the journal online (http://dx.doi. org/10.1136/bmjopen-2017019267).

Received 22 August 2017 Revised 24 November 2017 Accepted 27 November 2017

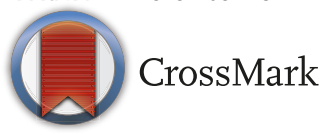

${ }^{1}$ Department of Health and Caring Sciences, Linnaeus University, Kalmar, Sweden ${ }^{2}$ Department of Orthopaedics, Danderyd Hospital, Stockholm, Sweden

${ }^{3}$ Department of Clinical Sciences, Danderyd Hospital, Karolinska Institutet, Stockholm, Sweden

${ }^{4}$ Department of Learning, Informatics, Management and Ethics, Karolinska Institutet, Stockholm, Sweden

${ }^{5}$ School of Technology and Health, Royal Institute of Technology, Stockholm, Sweden ${ }^{6}$ Departement of Health Care Sciences, Ersta Sköndal University College, Stockholm, Sweden

${ }^{7}$ Department of Anaesthesiology and Intensive Care, Department of Medical and Health Sciences, Linköping University, Linköping, Sweden

Correspondence to Dr Kristina Görel Ingegerd Schildmeijer; kristina.schildmeijer@Inu.se

\section{ABSTRACT}

Objective Home healthcare is an increasingly common part of healthcare. The patients are often aged, frail and have multiple diseases, and multiple caregivers are involved in their treatment. This study explores the origin, incidence, types and preventability of adverse events (AEs) that occur in patients receiving home healthcare. Design A study using retrospective record review and trigger tool methodology.

Setting and methods Ten teams with experience of home healthcare from nine regions across Sweden reviewed home healthcare records in a two-stage procedure using 38 predefined triggers in four modules. A random sample of records from 600 patients (aged 18 years or older) receiving home healthcare during 2015 were reviewed. Primary and secondary outcome measures The cumulative incidence of AEs found in patients receiving home healthcare; secondary measures were origin, types, severity of harm and preventability of the AEs.

Results The patients were aged $20-79$ years, 280 men and 320 women. The review teams identified 356 AEs in 226 (37.7\%; 95\% Cl 33.0 to 42.8) of the home healthcare records. Of these, 255 ( $71.6 \%$; $95 \% \mathrm{Cl} 63.2$ to 80.8$)$ were assessed as being preventable, and most (246, 69.1\%; $95 \% \mathrm{Cl} 60.9$ to 78.2 ) required extra healthcare visits or led to a prolonged period of healthcare. Most of the AEs (271, $76.1 \%$; $95 \%$ Cl 67.5 to 85.6 ) originated in home healthcare; the rest were detected during home healthcare but were related to care outside home healthcare. The most common AEs were healthcare-associated infections, falls and pressure ulcers.

Conclusions AEs in patients receiving home healthcare are common, mostly preventable and often cause temporary harm requiring extra healthcare resources. The most frequent types of AEs must be addressed and reduced through improvements in interprofessional collaboration. This is an important area for future studies.

\section{BACKGROUND}

Home healthcare is an increasingly common component of healthcare, as an alternative to hospitalisation. It includes a variety of healthcare interventions. The purpose can be curative, supportive, palliative or rehabilitative. The incidence and types of adverse events (AEs) in the acute care hospital setting

\section{Strengths and limitations of this study}

The review process was standardised and included a manual with detailed trigger definitions and preventability decision support.

- The review team members had long experience of home healthcare.

- Our recruitment of review teams was based on convenience sampling and did not enable review of a stratified sample of patients receiving home healthcare in Sweden.

- The results can only be generalised to facilities with similar organisations and clinical standards.

have been well-investigated in many countries and for several medical specialities. ${ }^{1-7}$ Despite the challenges related to an ageing population and citizens' demands to receive care at home, patient safety in home healthcare is rarely investigated. ${ }^{8-12}$ Incidence rates of AEs of up to $13 \%$ have been reported in a Canadian context ${ }^{811}$; falls and drug-related AEs are the most frequent.

Retrospective record review is commonly used to study patient harm using predefined triggers indicating potential AEs. More AEs are found through record review than through incident reporting systems. ${ }^{13}$ One of the most frequently used methods for retrospective record review is the Global Trigger Tool, ${ }^{14}$ which has been further adapted to suit different areas of healthcare.

The number of patients who are cared for in their homes is increasing. They are often aged, frail and have multiple diseases. Municipal home services provide assistance with activities in daily life, but medical and technical advances have also made it possible for advanced treatment of complex and long-term illnesses in patient homes. As the complexity of care increases, interaction between multiple professionals from different healthcare providers (ie, home healthcare, primary care, specialist care and social care) 
is critical for patient safety. New risks arise if communication and coordination of care is deficient. Thus, there is a need to further explore safety issues for patients receiving home healthcare, taking into consideration the complexity of having multiple caregivers involved in treatment and care. We have developed and validated a trigger tool intended for this group of patients. ${ }^{15}$ This study explores the origin, incidence, types and preventability of the AEs that occur in patients receiving home healthcare.

\section{METHODS}

\section{Study design}

This study used a retrospective record review design and was part of a validation study to validate the trigger tool for home healthcare settings. ${ }^{15}$

\section{Study setting}

The study was set in Sweden, where assistance with activities in daily life is provided in patient homes by unlicensed staff (eg, assistant nurses) on behalf of the municipal social care services. The municipalities are also usually responsible for providing home healthcare to the elderly. ${ }^{16}$ Their healthcare organisations include unlicensed assistant nurses, physiotherapists and occupational therapists, with registered nurses (RNs) providing the highest medical competence. The RNs have the overall responsibility for medication management and delivery of specialised healthcare in patient homes and consequently visit each patient less frequently than the unlicensed staff. When physician resources are necessary, they are usually provided by primary care physicians, but hospital physicians may also become involved. All physicians are employed by the county councils.

Home healthcare records are generally computerised. There are many different journal systems used in home healthcare in Sweden and the documentation routines, as well as access to these systems (read and write permissions), vary. Documentation from one caregiver, such as home healthcare, is not always accessible to healthcare professionals in other settings, such as staff at a hospital. As patients receiving home healthcare may be receiving care from several organisations simultaneously, we found it important to include all AEs documented in the home healthcare notes, irrespective of origin.

\section{Definitions}

In this study, an $\mathrm{AE}$ was defined as suffering, physical or psychological harm, illness or death caused by healthcare or social care that was not an inevitable consequence of the patient's condition or an expected effect of the treatment received by the patient because of her/his condition. A preventable $\mathrm{AE}$ was defined as an event that could have been prevented if adequate measures and/ or actions had been taken during the patient's contact with healthcare or social care. This definition is based on the terminology in the Swedish Patient Safety Act. ${ }^{17}$ AEs related to both acts of omission and acts of commission were included.

\section{Study sample, inclusion and exclusion criteria}

Ten review teams from different sites across Sweden were recruited using a convenience sampling strategy, invitations through personal contacts or by email via a national patient safety network. All review teams interested in participation were included. Seven teams were organised within municipalities and three teams were employed by county councils. The teams consisted of one to three RNs and one or two physicians. They all had long experience of working as RNs or physicians, and in the home healthcare context.

After approval from the regional ethical board, a random sample of 600 home healthcare records was reviewed during the period February to August 2016. All patients aged 18 years or older admitted to home healthcare during 2015 at the review sites were eligible for inclusion. The review included the period from admission (index admission) up to a maximum of 90 days after admission. If a patient was discharged from home healthcare and was readmitted within the 90-day period, the review of that patient continued. To be included as an $\mathrm{AE}$ in the study, one of the following criteria had to be met:

1. The AE occurred during the index admission, that is, within 90 days after admission in home healthcare, regardless of caregiver.

2. The AE derived from caregivers outside home healthcare (outpatient care, social care or in-hospital care), occurred within 30 days prior to the index admission and was detected during the index admission.

Randomisation of records was performed by one of the authors (MU), using an online randomiser, to ensure it was carried out in the same way for all review teams. Oversampling was carried out with 10 records per team. If a patient in the random sample was receiving limited home healthcare once or twice a week, for example, only blood pressure measurement or delivery of predispensed drugs, this patient was replaced by another random admission. AEs that gave symptoms $>90$ days after the index admission or that occurred were detected and for which treatment was completed before the index admission were excluded.

\section{Education of the review teams}

To ensure result validity and reliability, the review process was standardised in a written project manual, where the definitions and the inclusion and exclusion criteria were also included. A trigger manual was used, including trigger definitions and preventability decision support, as well as detailed examples that were discussed by the review teams before the study began. The team members underwent a mandatory 1 day education in the trigger tool methodology. Discussions were held to reach consensus about definitions, exclusion and inclusion criteria, interpretation and application of the triggers, assessment of AEs and preventability as well as how to use the two 
cases report forms. During the process of familiarisation with the methodology, each member of the review team independently reviewed six training records in order to achieve reliable reviews. This was followed by a consensus process with all teams including discussions regarding trigger outcome, assessments of AEs and preventability.

\section{Review process}

The review was performed in two stages. In most teams, the RNs carried out both primary and secondary reviews and later discussed the findings with the physicians. In some teams, the physicians carried out some of the primary as well as the secondary reviews.

In the primary review stage, the reviewers screened all records from their respective own setting for the presence of 38 predefined triggers categorised into four modules (table 1). A trigger is an indicator suggesting that an $\mathrm{AE}$ might have occurred during the inclusion period. For each trigger detected, the reviewer determined whether or not the trigger reflected the presence of a potential AE. Only records with triggers indicating a potential AE went forward to the secondary review stage. The reviewers also recorded demographic data. Starting from the index admission to home healthcare, a maximum of 90 days was reviewed. There was no time restriction for the review of each record in this stage. One reviewer carried out the primary review. To test inter-rater reliability, $10 \%$ of the records in the primary review process were reviewed by a second reviewer. Inter-rater reliability was assessed based on the reviewers' judgements regarding whether a record should be forwarded to secondary review. Discussions about individual judgements were held and when consensus was reached, the records were ready for the secondary review stage.

In the secondary review stage, each potential $\mathrm{AE}$ was scrutinised individually by the review team. To qualify as an $\mathrm{AE}$, a score of 3 or higher on a 4-point Likert scale was required ( 1 , the event was not related to healthcare/social care; 2 , the event was probably not related to healthcare/ social care; 3 , the event was probably related to healthcare/social care; 4 , the event was related to healthcare/ social care). The reviewer made a judgement whether or not the event qualified as an $\mathrm{AE}$. If it did, the $\mathrm{AE}$ was marked for further assessment. The preventability of an $\mathrm{AE}$ was judged on a similar 4-point scale: 1 , the $\mathrm{AE}$ was not preventable; 2, the $\mathrm{AE}$ was probably not preventable; 3 , the $\mathrm{AE}$ was probably preventable; 4 , the $\mathrm{AE}$ was preventable. $^{5}$ In the following, probably preventable (grade 3 ) and preventable (grade 4) AEs are referred to as preventable AEs.

The severity of harm was evaluated using two different scales. The first was the National Coordinating Council for Medication Error Reporting and Prevention (NCC MERP) Index ${ }^{18}$ which is used in the Global Trigger Tool. ${ }^{14}$ NCC MERP Index categories E-I were included, that is, those relating to harm (grade E, contributed to or resulted in temporary harm; grade F, contributed to or resulted in temporary harm to the patient and required outpatient, home health or hospital care or prolonged hospitalisation or extended the period of home healthcare; grade $\mathrm{G}$, contributed to or resulted in permanent patient harm; grade $\mathrm{H}$, life-saving intervention required within $60 \mathrm{~min}$; grade I, contributed to the patient's death). The second severity scale was that used in the Harvard Medical Practice Study (HMPS) ${ }^{19}$ and subsequently in several nationwide $\mathrm{AE}$ studies. It encompasses seven grades (minimal impairment, recovery within 1 month; moderate impairment, recovery within 1-6 months; moderate impairment, recovery within 6-12 months; permanent impairment, degree of disability $\leq 50 \%$; permanent impairment, degree of disability $>50 \%$; contributed to patient death; unable to determine). All reviewers also documented, for example, the type of AEs, as well as information on the origin of each $\mathrm{AE}$ (home healthcare, inpatient care, outpatient care or social care).

Access to various parts of the patients' medical records differed between review teams. Municipalities and county councils sometimes have separate medical record systems. Accordingly, some municipal review teams had to request physicians' notes and laboratory values, for example, because these were stored in their county council's record system.

All review teams were supported by record review experts in the research group who could answer questions. To ensure review quality, one expert (MU) monitored all reviews from the primary and secondary review stages for completeness and adherence to the trigger and $\mathrm{AE}$ definitions, and project manual. Any questions or discrepancies were referred back to the relevant team for resolution to make sure that the $\mathrm{AE}$ inclusion followed the project manual.

\section{Data analysis}

Data are presented as median (range), mean (SD) $(95 \% \mathrm{CI})$ or number $(\%)$. We calculated the cumulative incidence of AEs over the review period. Comparisons between groups were made using the Mann-Whitney $\mathrm{U}$ test or the $\chi^{2}$ test, as appropriate. A $\mathrm{P}$ value $<0.05$ was considered to be statistically significant. Agreement between reviewers was analysed using $\kappa$ statistics. All statistical calculations were performed using Statistica 64 V.13 (StatSoft, Oklahoma, USA).

\section{RESULTS}

A total of 600 patient records from home healthcare were reviewed; 280 of the patients were men, median age 79 years (range, 20-97 years), and 320 were women, median age 82 years (range, 29-99 years). The number of days reviewed was 40735 in total, with a median of 90 days per patient. Depending on patient discharge or death, the range of days reviewed varied between 1 and 90. Demographic data are shown in table 2.

The inter-rater reliability of the reviewers' judgements concerning if a record was to be forwarded to secondary review was $\kappa=0.801$ (substantial). 


\section{Table 1 List of triggers}

Care module Cardiac arrest and/or deterioration in vital signs

Deep venous thrombosis and/or pulmonary embolus

Pressure ulcer

Blood vessel, skin and/or tissue harm

Neurological impairment and/or harm

Fall

Healthcare-associated infection

Moderate/severe pain

Moderate/severe worry, anxiety, suffering, existential pain and/or psychological pain

Moderate/severe agitation and/or acute confusion/delirium

Undernutrition

Insufficient oral health

Moderate/severe gastrointestinal problem

Distended urinary bladder

Deviation from normal course after invasive/surgical treatment

Treatment

Advanced medical device

Threats, violence and/or improper contact

Self-inflicted harm

Escape from home/special

accommodation

Documentation of mistake or dissatisfaction with care

Other

Laboratory Abnormal glucose value
module

Increasing creatinine value

Abnormal potassium value

Abnormal sodium value

Abnormal calcium value

Medication Adverse drug event/adverse drug reaction

module

Drug that requires follow-up with blood sampling

Treatment with at least 10 drugs

Absence of in-depth drug review

Treatment with drugs that increase the risk for haemorrhage

\section{Drug management}

Continuity Unplanned change of care-providing unit and transition module

Unplanned contact with physician and/or registered nurse
Table 1 Continued

Absence of and/or deviation from care plan

Absence of a coordinated individual care plan when care is provided by several caregivers

Documentation related to insufficient coordination of care, communication and/ or information

Through the home healthcare records, 356 AEs were identified, affecting 226 patients (37.7\%; 95\% CI 33.0 to 42.8). This corresponds to a median of 1 (range, 1-7) AE per patient affected (table 3 ). Most were considered preventable (255, $71.6 \%$; $95 \%$ CI 63.2 to 80.8$)$. There was no difference in the incidence of AEs between men and women $(\mathrm{P}=0.72)$, or between patients aged 80 years or older and younger patients $(\mathrm{P}=0.12)$ (data not shown).

Of the AEs, 271 (76.1\%; 95\% CI 67.5 to 85.6) were related to home healthcare, $44(12.4 \%$; $95 \%$ CI 9.1 to 16.4) to in-hospital care, 23 (6.5\%; 95\% CI 4.2 to 9.5$)$ to social care and 12 (3.4\%; 95\% CI 1.8 to 5.7) to outpatient care. It was not possible to determine from the documentation where the remaining $6(1.7 \%$; $95 \%$ CI 0.7 to 3.5$)$ AEs had originated. There was no difference in preventability $(\mathrm{P}=0.97)$ between AEs originating in home healthcare or outside home healthcare (data not shown).

On the NCC MERP scale, 102 (28.6\%; 95\% CI 23.5 to 34.6) of all AEs resulted in temporary harm to the patient and 246 (69.1\%; 95\% CI 60.9 to 78.2$)$ in temporary harm that required extra healthcare visits or a prolonged care period. The HMPS scale showed that 213 (59.8\%; 95\% CI 52.2 to 68.3 ) of all AEs were minor with recovery within 1 month (table 4 ).

The most common types of AEs were healthcare-associated infections, falls and pressure ulcers (table 5). There were no differences in the number of such AEs between men and women or between patients aged 80 years or older and younger patients (data not shown). The probability of falls being preventable was $43.9 \%$; $95 \%$ CI 30.0 to 62.3 , whereas the majority of the other types of AEs were considered preventable to a greater extent. There was no difference in the type of AEs between those originating in home healthcare and those from care given outside home healthcare $(\mathrm{P}=0.52)$.

Forty-one $(18.1 \%)$ of the AEs in the home healthcare setting required a median of one (range, 1-5) additional physician visit(s) in the outpatient setting, 40 (14.8\%) required a median of 1 (range, 1-9) additional physician visit(s) in the home healthcare setting and 37 (13.7\%) required hospital care for a median of 6 days (range, 1-41 days). There were no significant differences compared with AEs outside home healthcare: 7 (8.2\%) (median, 1 ; range, 1-2) required additional physician visit(s) in the outpatient setting; 11 (12.9\%) (median, 1; range, 1-11) required additional physician visit(s) in the home 


\section{Table 2 Demographic data}

\begin{tabular}{|c|c|}
\hline Parameter & Value \\
\hline Men/women, n (\%) & $280(46.7) / 320(53.3)$ \\
\hline Age in years, median (range) & $80.5(20-99)$ \\
\hline Reviewed days, median (range) & $90(1-90)$ \\
\hline \multicolumn{2}{|l|}{ Referral to home healthcare from } \\
\hline Hospital care, n (\%) & $300(50.0)$ \\
\hline Outpatient care, n (\%) & 212 (35.3) \\
\hline Not possible to determine, $\mathrm{n}(\%)$ & $88(14.7)$ \\
\hline \multicolumn{2}{|l|}{$\begin{array}{l}\text { Medical diagnosis at home healthcare } \\
\text { admission* }\end{array}$} \\
\hline Malignancy, n (\%) & $253(42.2)$ \\
\hline Cardiovascular disease, n (\%) & $119(19.8)$ \\
\hline Confusion, dementia, n (\%) & $102(17.0)$ \\
\hline Diabetes, n (\%) & $51(8.5)$ \\
\hline Skin wound, pressure ulcer, n (\%) & $38(6.3)$ \\
\hline Stroke, n (\%) & $36(6.0)$ \\
\hline Pulmonary disease, $\mathrm{n}(\%)$ & $35(5.8)$ \\
\hline Neurological disease, n (\%) & $33(5.5)$ \\
\hline \multicolumn{2}{|l|}{$\begin{array}{l}\text { Medical needs at home healthcare } \\
\text { admission } \dagger\end{array}$} \\
\hline Medication assistance, n (\%) & $233(38.8)$ \\
\hline Palliative care, n (\%) & $144(24.0)$ \\
\hline Activities of daily living, $n(\%)$ & $111(18.5)$ \\
\hline Laboratory sampling, n (\%) & $88(14.7)$ \\
\hline $\begin{array}{l}\text { Wound care, assistance with } \\
\text { compression stockings, n (\%) }\end{array}$ & $74(12.3)$ \\
\hline $\begin{array}{l}\text { Assistance with advanced medical } \\
\text { devices, } \mathrm{n}(\%)\end{array}$ & $62(10.3)$ \\
\hline $\begin{array}{l}\text { Rehabilitation, home modifications, } \\
\text { means testing, } \mathrm{n}(\%)\end{array}$ & $51(8.5)$ \\
\hline Pain relief, n (\%) & $39(6.5)$ \\
\hline
\end{tabular}

Social situation at home healthcare admission

\begin{tabular}{lc} 
Patient's own home, lives alone, & $265(44.2)$ \\
$\mathrm{n}(\%)$ & \\
$\begin{array}{l}\text { Patient's own home, cohabiting, } \\
\text { n (\%) }\end{array}$ & $257(42.8)$ \\
$\begin{array}{l}\text { Home for medical healthcare, } \\
\text { assistance } 24 / 7, \mathrm{n}(\%)\end{array}$ & $50(8.3)$ \\
\hline & $28(4.7)$ \\
\hline
\end{tabular}

${ }^{*}$ Medical diagnosis affecting $>5 \%$ of patients. A patient could have several diagnoses.

†Medical needs for $>5 \%$ of patients. A patient could have several medical needs.

healthcare setting; 13 (15.3\%) required hospital care for a median of 7 days (range, $2-10$ days).

\section{DISCUSSION}

This study is the first to assess AEs in patients receiving home healthcare across different parts of Sweden through the use of retrospective record review. Our main findings are that AEs affect over a third of these patients, are deemed to be mostly preventable and result in temporary harm to the patient requiring extra healthcare resources. A quarter of the AEs detected in home healthcare originated in other healthcare settings. We found no differences in the type of AEs, or their severity or preventability, depending on origin.

There are few studies investigating AEs in home healthcare with which to compare our findings. The incidence of AEs, $37.7 \%$, is much higher than the $4 \%-13 \%$ reported by other studies. ${ }^{8-11}$ It is difficult to compare the rates, as the differences may be due to varying services, patient characteristics, and methods of record review, as well as the definition of an $\mathrm{AE}$ and the inclusion criteria used. It is also difficult to compare the rates for the home healthcare setting with in-hospital AE rates, because the home healthcare provider may not continuously observe the patients and the healthcare environment. The majority of the identified AEs were minor and transient. In a comparison of serious AEs (recovery within 6-12 months, permanent disability or death) by recalculating their respective prevalence, there seem to be no obvious differences between our study and an earlier Swedish in-hospital study or Canadian home healthcare. ${ }^{18}$

Patients receiving home healthcare are often old and frail and frequently have concomitant contact with multiple caregivers. We have shown that almost $25 \%$ of AEs found in patients in home healthcare originated in care given in other settings. AEs such as pressure ulcers or infections impose an additional burden on the home healthcare organisation with its limited access to RNs and physicians. This finding also highlights the importance of passing knowledge about AEs between caregivers. The findings imply that all sections of healthcare should be aware of these most common AEs and preventive measures that can be taken along a patient's healthcare journey.

Almost three out of four AEs, regardless of origin, were judged by the review teams in our study to be preventable. This is higher than the $33 \%-56 \%$ previously reported in the home healthcare setting, ${ }^{89}$ but is in line with many hospital record reviews. ${ }^{15620}$ Risk reduction in patient homes is not directly transferable from hospital care. The possibility of conflict between patient autonomy and safety should be considered in the home care setting. Patients are the hosts of the care environment and supervision from healthcare personnel is mostly limited to short visits. Preventive safety measures in a patient's home require true patient involvement, taking the patient's values and integrity into consideration. For instance, removing carpets to prevent falls, one of the AEs with the lowest preventability ratings must be weighed against a patient's own wishes.

Our findings of healthcare-associated infections, falls, pressure ulcers and skin breakdown as the most common AEs are largely consistent with a Canadian review of 1200 records from 2009 to 2010, which reported falls, wound 
Table 3 Adverse events (AEs) detected in patients receiving home healthcare classified by origin $(n=600)$

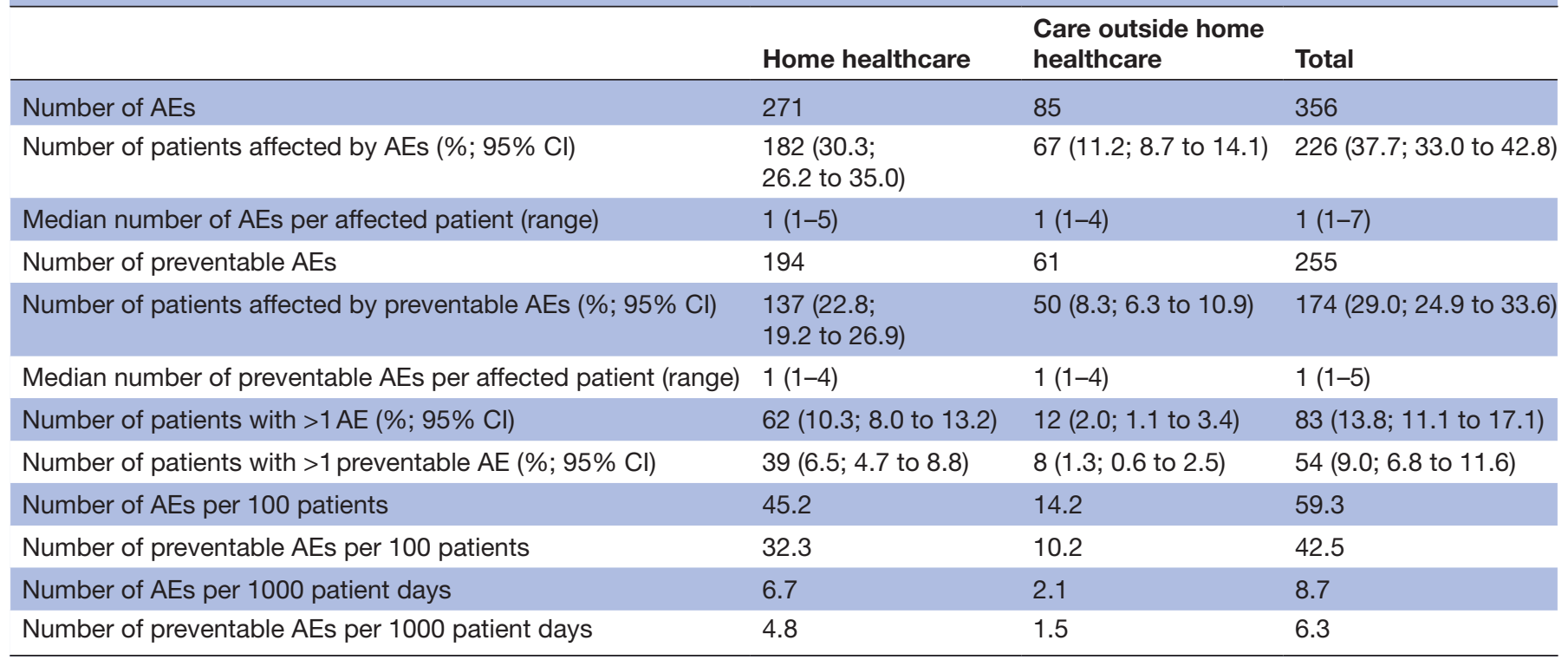

infections, psychosocial, behavioural or mental health problems, or medication-related AEs as the most prominent findings. ${ }^{9}$ We chose to not to use "medication-related AEs' as a separate AE group, since we regarded medication as a cause of AEs. Medication-caused AEs can be found among, for example, falls, severe constipation and oral candidiasis. Other studies also report injurious falls as the most common AE in home healthcare. ${ }^{1121}$ Decline in physical function is a prevalent safety risk. ${ }^{10}$ Falls are also associated with increased risk of admission to longterm care and death. ${ }^{11}$ This emphasises the need to find effective strategies for prevention of falls. Preventive strategies for pressure ulcers and skin breakdown ${ }^{8}$ also need to be identified. Patients in home healthcare may have several well-known risk factors for pressure ulcers. In one study, one-tenth of AEs in patients receiving home healthcare fell into the category general decline. ${ }^{8}$ The ageing patient is at risk for weight loss and malnutrition. Doran et $a l^{10}$ noted that unintended weight loss accounted for $10 \%$ of the safety problems in home healthcare. Patients receiving home healthcare are often affected by cancer, where weight loss is a well-known problem. ${ }^{10} 22$ Routines for the prevention of weight loss are important. Interventions can include energy-rich and protein-rich food, food with a particular texture, artificial nutrition, information about eating habits and checking the patient's weight on a regular basis. ${ }^{23}$

Healthcare-associated infections are common in both home healthcare and hospital care. ${ }^{124}$ Falls and pressure ulcers are also common in hospitalised patients. However, the type of AEs in home healthcare differ from that in hospital care in other aspects. Surgical/procedural AEs and distended urinary bladder are more common in hospital care. ${ }^{16212526}$

We found that more than half of the AEs caused minimal impairment, with recovery within 1 month. This is in contrast to the findings of Sears $e t a l^{8}$ where one-quarter of the AEs caused slight impairment and half resulted in moderate-to-serious impairment or death. One explanation for the difference could be that we found three times more AEs and probably included less severe AEs. Sears et $a l^{8}$ only included AEs that required the use of additional healthcare resources. Interventions in connection with AEs are a resource-consuming burden to healthcare. In order to get a broader and more proactive approach to patient safety, we found it important to include AEs that caused temporary harm without requiring extra visits or a prolonged healthcare period.

We chose to review a period up to a maximum of 90 days from the start of a randomly chosen home healthcare period and included all AEs regardless of caregiver. If a patient was hospitalised and returned to home healthcare during that period, we included the new home healthcare period(s). The Institute for Healthcare Improvement has developed a trigger tool for skilled nursing facilities recommending that only the first 30 days of an admission are reviewed. ${ }^{27}$ Blais $e t a \theta^{\theta}$ included a period of up to 12 months preceding discharge for review and also included a 6-month period after discharge from the index admission. There is no consensus regarding which triggers to use in different settings. ${ }^{28}$ The same applies for reporting of $\mathrm{AE}$ rates, as well as characterisation of AEs, which makes comparisons difficult. As demand for home healthcare and interest in home healthcare safety increase, reliable and validated safety tools are warranted.

The strengths of this study include having 10 teams from different parts of Sweden to review 600 records, which served to give an overview of AEs occurring in home healthcare settings. In accordance with the Global Trigger Tool methodology and as patients receiving home healthcare sometimes need parallel interventions from caregivers outside home healthcare, we chose a broader perspective on patient safety and included all AEs that occurred and/or were detected during the 


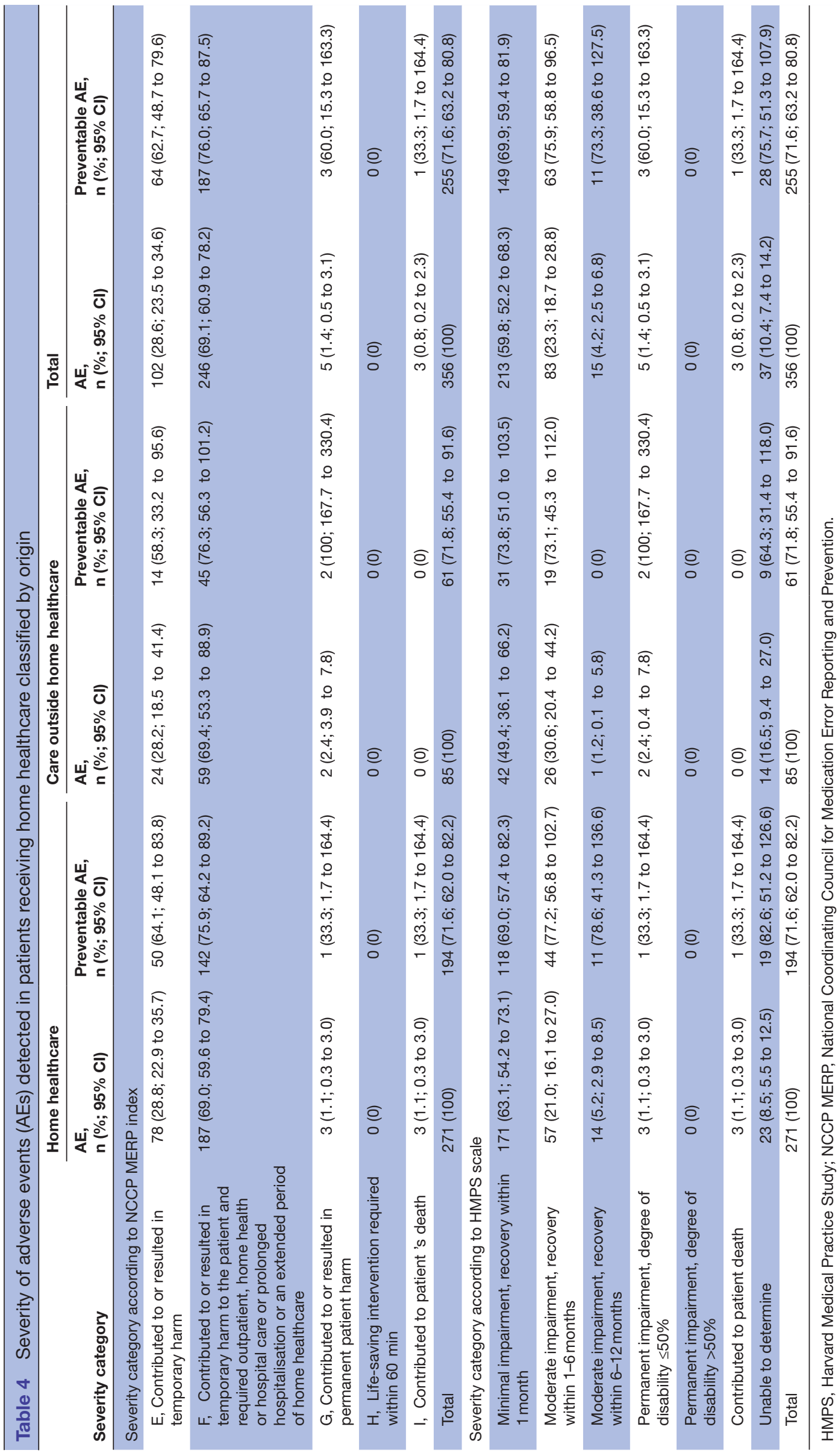


Table 5 Types of adverse events (AEs) detected in patients receiving home healthcare, the origin and the proportion of preventable AEs

\begin{tabular}{|c|c|c|c|c|}
\hline Type of AE & $\begin{array}{l}\text { Home healthcare, } \\
\text { AEs } \\
\text { n (\%; } 95 \% \mathrm{Cl})\end{array}$ & $\begin{array}{l}\text { Care outside home } \\
\text { healthcare, AEs } \\
\text { n (\%; } 95 \% \text { Cl) }\end{array}$ & $\begin{array}{l}\text { Total, AEs } \\
\text { n (\%; } 95 \% \mathrm{Cl})\end{array}$ & $\begin{array}{l}\text { Total preventable AEs, } \\
\text { n (\%; } 95 \% \mathrm{Cl})\end{array}$ \\
\hline $\begin{array}{l}\text { Healthcare-associated } \\
\text { infections }\end{array}$ & $59(21.8 ; 16.7$ to 27.9$)$ & $13(15.3 ; 8.5$ to 25.5$)$ & $72(20.2 ; 15.9$ to 25.3$)$ & $46(63.9 ; 47.3$ to 84.5$)$ \\
\hline Oral candidiasis & $12(25.4)$ & $1(7.7)$ & $13(18.1)$ & $6(46.1)$ \\
\hline Urinary tract infection & $9(15.2)$ & $2(15.4)$ & $11(15.3)$ & $8(72.7)$ \\
\hline Pneumonia & $10(16.9)$ & $1(7.7)$ & $11(15.3)$ & $8(72.7)$ \\
\hline Wound infection & $9(15.2)$ & $3(23.1)$ & $12(16.6)$ & $12(100.0)$ \\
\hline Sepsis & $5(8.5)$ & $1(7.7)$ & $6(8.3)$ & $1(16.7)$ \\
\hline $\begin{array}{l}\text { Candidiasis of the } \\
\text { skin }\end{array}$ & $5(8.5)$ & $1(7.7)$ & $6(8.3)$ & $6(100.0)$ \\
\hline Others & $9(15.2)$ & $4(30.8)$ & $13(18.1)$ & $5(38.5)$ \\
\hline Falls & $51(18.8 ; 14.2$ to 24.6$)$ & 15 (17.6; 10.2 to 28.4$)$ & $66(18.5 ; 14.4$ to 23.4$)$ & $29(43.9 ; 30.0$ to 62.3$)$ \\
\hline Fracture & $7(13.7)$ & $4(26.7)$ & $11(16.7)$ & $6(54.5)$ \\
\hline Skin wound & $33(64.7)$ & $7(46.7)$ & 40 (60.6) & $14(35.0)$ \\
\hline Pain & $11(21.6)$ & $3(30.0)$ & $14(21.2)$ & $8(57.1)$ \\
\hline Not specified & $0(0)$ & $1(6.7)$ & $1(1.5)$ & $1(100.0)$ \\
\hline Pressure ulcers & $46(17.0 ; 12.6$ to 22.4$)$ & $16(18.8 ; 11.1$ to 29.9$)$ & $62(17.4 ; 13.5$ to 22.2$)$ & $52(83.9 ; 63.3$ to 109.1$)$ \\
\hline Category 1 & $20(43.5)$ & $4(25.0)$ & $24(38.7)$ & 21 (87.5) \\
\hline Category 2 & 17 (37.0) & $8(50.0)$ & $25(40.3)$ & $19(76.0)$ \\
\hline Category 3 & $3(6.5)$ & $2(12.5)$ & $5(8.0)$ & $4(80.0)$ \\
\hline Category 4 & $2(4.3)$ & $0(0)$ & $2(3.2)$ & $2(100.0)$ \\
\hline Category unknown & $4(8.7)$ & $2(12.5)$ & $6(9.7)$ & $6(100.0)$ \\
\hline $\begin{array}{l}\text { Skin, vessel or tissue } \\
\text { harm }\end{array}$ & $25(9.2 ; 6.1$ to 13.4$)$ & $8(9.4 ; 4.4$ to 17.9$)$ & $33(9.3 ; 6.5$ to 12.9$)$ & $27(81.8 ; 55.0$ to 117.4$)$ \\
\hline Skin harm & $18(72.0)$ & $4(25.0)$ & $22(66.7)$ & $18(81.8)$ \\
\hline Vessel harm & $4(16.0)$ & $1(12.5)$ & $5(15.2)$ & $3(80.0)$ \\
\hline Tissue harm & $3(12.0)$ & $3(37.5)$ & $6(18.2)$ & $6(100.0)$ \\
\hline Pain & 17 (6.3; 3.8 to 9.8$)$ & $6(7.1 ; 2.9$ to 14.7$)$ & $23(6.5 ; 4.2$ to 9.5$)$ & $21(91.3 ; 58.0$ to 137.2$)$ \\
\hline Psychological harm & $12(4.4 ; 2.4$ to 7.5$)$ & $6(7.1 ; 2.9$ to 14.7$)$ & $18(5.1 ; 3.1$ to 7.8$)$ & $14(77.8 ; 44.3$ to 127.4$)$ \\
\hline Other & $10(3.7 ; 1.9$ to 6.6$)$ & $1(1.2 ; 0.1$ to 5.8$)$ & $11(3.1 ; 1.6$ to 5.4$)$ & $10(90.1 ; 46.2$ to 162.0$)$ \\
\hline Neurological harm & 7 (2.6; 1.1 to 5.1$)$ & $3(3.5 ; 0.9$ to 9.6$)$ & $10(2.8 ; 1.4$ to 5.0$)$ & 9 (90.0; 43.9 to 165.2$)$ \\
\hline $\begin{array}{l}\text { Haemorrhage (not } \\
\text { related to surgery) }\end{array}$ & $7(2.6 ; 1.1$ to 5.1$)$ & $3(3.5 ; 0.9$ to 9.6$)$ & $10(2.8 ; 1.4$ to 5.0$)$ & $4(40.0 ; 12.7$ to 96.5$)$ \\
\hline Failure in vital signs & 7 (2.6; 1.1 to 5.1$)$ & $3(3.5 ; 0.9$ to 9.6$)$ & $10(2.8 ; 1.4$ to 5.0$)$ & $9(90.0 ; 43.9$ to 165.2$)$ \\
\hline $\begin{array}{l}\text { Weight loss, nutrition- } \\
\text { related } A E\end{array}$ & $5(1.8 ; 0.7$ to 4.1$)$ & $3(3.5 ; 0.9$ to 9.6$)$ & $8(2.2 ; 1.0$ to 4.3$)$ & $7(87.5 ; 38.3$ to 173.1$)$ \\
\hline $\begin{array}{l}\text { General deterioration in } \\
\text { health status }\end{array}$ & 7 (2.6; 1.1 to 5.1$)$ & $0(0)$ & $7(2.0 ; 0.9$ to 3.9$)$ & 7 (100.0; 43.7 to 197.8 \\
\hline Severe constipation & $5(1.8 ; 0.7$ to 4.1$)$ & $0(0)$ & $5(1.4 ; 0.5$ to 3.1$)$ & 5 (100.0; 36.6 to 221.7 \\
\hline Severe vomiting & $4(1.5 ; 0.5$ to 3.6$)$ & $0(0)$ & $4(1.1 ; 0.4$ to 2.7$)$ & $3(75.0 ; 19.1$ to 204.1$)$ \\
\hline $\begin{array}{l}\text { Affected laboratory } \\
\text { values }\end{array}$ & $3(1.1 ; 0.3$ to 3.0$)$ & $1(1.2 ; 0.1$ to 5.8$)$ & $4(1.1 ; 0.4$ to 2.7$)$ & $4(100.0 ; 31.8$ to 241.2 \\
\hline Allergic reaction & $1(0.4 ; 0.0$ to 1.8$)$ & $2(2.4 ; 0.4$ to 7.8$)$ & $3(0.8 ; 0.2$ to 2.3$)$ & $1(33.3 ; 1.7$ to 164.4$)$ \\
\hline Severe diarrhoea & $1(0.4 ; 0.0$ to 1.8$)$ & $2(2.4 ; 0.4$ to 7.8$)$ & $3(0.8 ; 0.2$ to 2.3$)$ & 1 (33.3; 1.7 to 164.4$)$ \\
\hline $\begin{array}{l}\text { Distended urinary } \\
\text { bladder }\end{array}$ & $2(0.7 ; 0.1$ to 2.4$)$ & $2(2.4 ; 0.4$ to 7.8$)$ & $4(1.2 ; 0.4$ to 2.7$)$ & $4(100 ; 31.8$ to 241.2$)$ \\
\hline
\end{tabular}


Table 5 Continued

\begin{tabular}{|c|c|c|c|c|}
\hline Type of AE & $\begin{array}{l}\text { Home healthcare, } \\
\text { AEs } \\
\text { n (\%; } 95 \% \mathrm{Cl})\end{array}$ & $\begin{array}{l}\text { Care outside home } \\
\text { healthcare, AEs } \\
\text { n ( } \% ; 95 \% \mathrm{Cl})\end{array}$ & $\begin{array}{l}\text { Total, AEs } \\
\text { n (\%; } 95 \% \mathrm{CI})\end{array}$ & $\begin{array}{l}\text { Total preventable AEs, } \\
\text { n (\%; } 95 \% \mathrm{Cl})\end{array}$ \\
\hline Dehydration & $1(0.4 ; 0.0$ to 1.8$)$ & $1(1.2 ; 0.1$ to 5.8$)$ & $2(0.6 ; 0.1$ to 1.9$)$ & $1(50.0 ; 2.5$ to 246.6$)$ \\
\hline Attempted suicide & $1(0.4 ; 0.0$ to 1.8$)$ & $0(0)$ & $1(0.3 ; 0.0$ to 1.4$)$ & 1 (100.0; 5.0 to 493.2$)$ \\
\hline Total & $271(100.0)$ & $85(100.0)$ & $356(100.0)$ & $255(71.6 ; 63.2$ to 80.8$)$ \\
\hline
\end{tabular}

90-day review period. We modified our definition based on NCC MERP classification E to include all AEs that resulted in temporary harm to the patient, regardless of whether an intervention was documented or not. We regard this as an improvement from a patient perspective, as it contributes to the identification of risk areas. To adapt to the patient perspective and visualise the extra resources required due to AEs, we also expanded NCC MERP classification $\mathrm{F}$ to include extra visits within home healthcare and outpatient care. This study also has a number of limitations. We did not use a stratified sample of records for all patients receiving home healthcare in Sweden. As the review was a part of the development and validation of a trigger tool suited for home healthcare, we aimed for review teams with an interest in patient safety. The 600 records were randomised from the 10 sites and gave an overview of AEs occurring in home healthcare. As this study was part of a validation study and forms a basis for a national trigger tool for home healthcare, we aimed for richer review material and limited inclusion by excluding records from patients receiving very sparse and infrequent home healthcare. This exclusion criterion was defined using examples only. Defining a minimum level of home healthcare services for inclusion to the study would have been preferable. The review process had only two primary reviewers reviewing the same sample in $10 \%$ of the records. In any study based on record review, only AEs that are noted in the record can be found. There is a risk of under-reporting of AEs as the reviewer teams screened records from their own setting. On the other hand, they could have found more AEs as they have context information that is not stated in the record. Finally, generalisability may be limited if home healthcare services have differing clinical standards.

\section{CONCLUSIONS}

AEs in patients receiving home healthcare are common, mostly preventable and often result in temporary harm that requires extra healthcare resources. As in hospital care, healthcare-associated infections, falls and pressure ulcers are common AEs. The latter two are even more common in home healthcare, as is harm to skin, vessels and tissue. This implies that we must address and reduce these AEs through improvements identified in collaborations between professionals. This is an important area for future studies.
Contributors KGIS, MU, ME, ML and LN designed and conducted the study. KGIS, $\mathrm{MU}$ and $\mathrm{LN}$ undertook the initial interpretation of the data, which was followed by discussions with all the authors. All authors drafted the manuscript and were part of the revision process. All authors agreed to the final version of the manuscript before submission.

Funding Financial support was provided through FORSS (No 470161) - Medical Research Council of Southeast Sweden and the Region Östergötland (Li0-537211). The funders have neither been involved in any part of the study, nor in writing the manuscript or the decision to submit the manuscript for publication.

\section{Competing interests None declared.}

Ethics approval Ethical permission was obtained from the Regional Ethical Board of Linköping University, Sweden (№ 2014/150-31).

Provenance and peer review Not commissioned; externally peer reviewed. Data sharing statement Additional data can be available from the first author.

Open Access This is an Open Access article distributed in accordance with the Creative Commons Attribution Non Commercial (CC BY-NC 4.0) license, which permits others to distribute, remix, adapt, build upon this work non-commercially, and license their derivative works on different terms, provided the original work is properly cited and the use is non-commercial. See: http://creativecommons.org/ licenses/by-nc/4.0/

(c) Article author(s) (or their employer(s) unless otherwise stated in the text of the article) 2018. All rights reserved. No commercial use is permitted unless otherwise expressly granted.

\section{REFERENCES}

1. Soop M, Fryksmark U, Köster M, et al. The incidence of adverse events in Swedish hospitals: a retrospective medical record review study. Int J Qual Health Care 2009;21:285-91.

2. von Plessen C, Kodal AM, Anhøj J. Experiences with global trigger tool reviews in five Danish hospitals: an implementation study. BMJ Open 2012;2:e001324-8.

3. Resar RK, Rozich JD, Simmonds T, et al. A trigger tool to identify adverse events in the intensive care unit. Jt Comm J Qual Patient Saf 2006;32:585-90.

4. Kaafarani HM, Rosen AK, Nebeker JR, et al. Development of trigger tools for surveillance of adverse events in ambulatory surgery. Qual Saf Health Care 2010;19:425-9.

5. Unbeck M, Lindemalm S, Nydert P, et al. Validation of triggers and development of a pediatric trigger tool to identify adverse events. BMC Health Serv Res 2014;14:655.

6. Nilsson L, Risberg MB, Montgomery A, et al. Preventable adverse events in surgical care in Sweden: a nationwide review of patient notes. Medicine 2016;95:e3047.

7. Mattsson TO, Knudsen JL, Lauritsen J, et al. Assessment of the global trigger tool to measure, monitor and evaluate patient safety in cancer patients: reliability concerns are raised. BMJ Qual Saf 2013;22:571-9.

8. Sears N, Baker GR, Barnsley J, et al. The incidence of adverse events among home care patients. Int J Qual Health Care 2013;25:16-28.

9. Blais R, Sears NA, Doran D, et al. Assessing adverse events among home care clients in three Canadian provinces using chart review. BMJ Qual Saf 2013;22:989-97.

10. Doran DM, Hirdes J, Blais R, et al. The nature of safety problems among Canadian homecare clients: evidence from the RAI-HC reporting system. J Nurs Manag 2009;17:165-74. 
11. Doran DM, Hirdes JP, Blais R, et al. Adverse events among Ontario home care clients associated with emergency room visit or hospitalization: a retrospective cohort study. BMC Health Serv Res 2013;13:227.

12. Madigan EA. A description of adverse events in home healthcare. Home Healthc Nurse 2007;25:191-7.

13. Classen DC, Resar R, Griffin F, et al. 'Global trigger tool' shows that adverse events in hospitals may be ten times greater than previously measured. Health Aff 2011;30:581-9.

14. Griffin F, Resar R. IHI global trigger tool for measuring adverse events. 2nd edn. Cambridge, MA: Institute for Healthcare Improvement, 2009.

15. Lindblad M, Schildmeijer K, Nilsson L, et al. Development and validation of a trigger tool to identify adverse events and no-harm incidents that affect patients admitted to home healthcare. BMJ Qual and Saf 2017.doi: 10.1136/bmjqs-2017-006755. [Epub ahead of print 29 Sep 2017].

16. Anell $A$, Glenngård $A H$, Merkur $\mathrm{S}$. Sweden health system review. Health Syst Transit 2012;14:1-159.

17. Ministry of Social. Patientsäkerhetslagen [patient safety act]. 2010. SFS 2010:659 https://www.riksdagen.se/sv/dokument-lagar/ dokument/svensk-forfattningssamling/patientsakerhetslag-2010659_ sfs-2010-659 (accessed 20 Mar 2017).

18. NCC MERP. NCC MERP index for categorizing medication errors. http://www.nccmerp.org/sites/default/files/indexBW2001-06-12.pdf (accessed 26 Sept 2017).
19. Brennan TA, Leape LL, Laird NM, et al. Incidence of adverse events and negligence in hospitalized patients. Results of the Harvard Medical Practice Study I. N Engl J Med 1991;324:370-6.

20. Kennerly DA, Saldaña M, Kudyakov R, et al. Description and evaluation of adaptations to the global trigger tool to enhance value to adverse event reduction efforts. J Patient Saf 2013;9:87-95.

21. Johnson KG. Adverse events among winnipeg home care clients. Healthc Q 2006;9:127-34.

22. Tisdale MJ. Cachexia in cancer patients. Nat Rev Cancer 2002;2:862-71.

23. Alibhai SM, Greenwood C, Payette H. An approach to the management of unintentional weight loss in elderly people. CMAJ 2005;172:773-80.

24. Deilkås ET, Bukholm G, Lindstrøm JC, et al. Monitoring adverse events in Norwegian hospitals from 2010 to 2013. BMJ Open 2015;5:e008576.

25. Unbeck M, Muren O, Lillkrona U. Identification of adverse events at an orthopedics department in Sweden. Acta Orthop 2008;79:396-403.

26. Unbeck M, Dalen N, Muren O, et al. Healthcare processes must be improved to reduce the occurrence of orthopaedic adverse events. Scand J Caring Sci 2010;24:671-7.

27. Adler L, Moore J, Federico F. IHI skilled nursing facility trigger tool for measuring adverse events. Cambridge, MA: Institute for Healthcare Improvement, 2015.

28. Hibbert PD, Molloy CJ, Hooper TD, et al. The application of the Global Trigger Tool: a systematic review. Int J Qual Health Care 2016;28:640-9. 